TAO, Vol. 16, No. 5, 935-957, December 2005

\title{
Impact of Soil Moisture on Regional Spectral Model Simulations for South America
}

\author{
Shyh-Chin Chen ${ }^{1, *}$ and John O. Roads ${ }^{2}$
}

(Manuscript received 28 February 2004, in final form 8 July 2005)

\begin{abstract}
A two-year (March 1997 - March 1999) regional simulation using the regional spectral model (RSM) with a 50-km grid covering South America, bounded and initialized by the NCEP/NCAR 28 vertical levels T62 spectral resolution reanalyses is described.

Initial experiments showed that the RSM had a severe dry bias in the soil moisture that adversely impacted the precipitation. The dry bias was presumably a response to the positive feedback between imperfect model parameterization schemes and the soil moisture module in the model. This dry bias was corrected in two additional experiments by modifying the deep soil moisture in the model during the integration. The first experiment prescribed the daily soil moisture in the deep second layer from the driving reanalysis; the second experiment utilized observed precipitation, to interactively correct the deep soil moisture during the integration. Both experiments had less bias than the reanalysis precipitation. However, regional precipitation temporal variations were only as good as, if not marginally better than, the reanalysis precipitation when validated against observed 0.5-degree gridded data. The experiment with interactively corrected soil moisture provided the best simulation and had better anomaly threat scores at all precipitation intensities than the one with the specified soil moisture values from the reanalysis. Until current coupled land-atmosphere regional model soil moisture simulation biases can be substantially reduced, they can at least be corrected by using observed precipitation.
\end{abstract}

(Key words: Numerical modeling, Regional climate, Soil moisture)

\footnotetext{
${ }^{1}$ USDA Forest Service, Riverside, California, USA

2 Experimental Climate Prediction Center, University of California, San Diego, La Jolla, California, USA

* Corresponding author address: Prof. Shyh-Chin Chen, USDA Forest Service, Riverside, California, USA; E-mail: schen@fs.fed.us
} 


\section{INTRODUCTION}

There is great expectation that regional climate models will eventually provide useful added high-resolution information from global-scale reanalysis and climate forecasts for regional applications (Nobre et al. 2001; Roads et al. 2002). In fact, there has been some success in dynamical downscaling in precipitation and temperature simulations over complex terrain regions such as the US West (Chen et al. 1999; Leung and Ghan 1999; Kim et al. 2000). While the potential for regional climate modeling is slowly being realized (e.g., Takle et al. 1999; Giorgi et al. 2001), many modeling defects still remain to be resolved (Leung et al. 2003). Unfortunately, increased skill of precipitation output from some regional models is still marginal (e.g., Roads et al. 2002) when validated against observations.

An inter-comparison effort over South America with four regional climate models was recently carried out (Roads et al. 2003). This inter-comparison showed that all of the participating regional models had noticeable defects in precipitation simulation, but the largest contribution to the systematic error was presumably inherited from the driving global-scale circulation. The inter-comparison also indicated that the relatively small decrease in skill may be related in part to the inadequate use of surface boundary conditions, such as vegetation type, soil texture, and soil moisture content, which control the surface fluxes and hence the local precipitation variability. Soil moisture content is an especially important variable, as previously suggested by McCumber and Pielke (1981) from experiments with a mesoscale numerical weather prediction model. Although the impact of soil moisture is not geographically uniform (Kanamitsu and Mo 2003; Mo and Juang 2003), it does have a strong influence on simulations of mesoscale severe storms (Lanicci et al. 1987), regional climate precipitation simulations over the United States (Giorgi et al. 1996; Bosilovch and Sun 1999), and extended range forecasts over South America (Chou et al. 2000).

Roads et al. (2003) used prescribed layer 2 soil moisture from the driving global analysis in the regional spectral model (RSM) which was originally developed at the National Centers for Environmental Prediction (NCEP) (Juang and Kanamitsu 1994; Juang et al. 1997), for inter-comparison over South America. Although this method effectively avoided the original RSM dry bias over the simulation region, there was concern that the forcing reanalysis deep soil moisture lacked the inter-annual variation (Roads et al. 1999) magnitudes needed to properly simulate the hydroclimate over this region. To further address this shortcoming, we compare here the skill of the regional simulations over South America with three experiments: one with no soil moisture correction, one with soil moisture specified from the NCEP/NCAR reanalysis (described previously by Roads et al. 2003), and one with an interactive correction scheme making use of observed precipitation. Observed high-resolution gridded precipitation data (that subsequently became available once these simulations were finished) as well as the reanalysis precipitation will be used to evaluate the additional regional model skill. From these three experiments, perhaps we can gauge the importance of the soil water content in terms of its amount and variation to the precipitation simulation over this region. The latter two soil moisture experiments effectively remedy a well-known dry bias of NCEP models (e.g., Roads et al. 1999).

A brief summary of the RSM is given in section 2 . The description of the driving reanaly- 
sis and validating observations are provided in section 3. Section 4 describes the design of the experiments, including the skill measures. Section 5 shows the results, and conclusions are provided in section 6 .

\section{REGIONAL SPECTRAL MODEL}

The regional model used in this study is the Scripps Experimental Climate Prediction Center (ECPC) version (RSM97) RSM. A previous version of the RSM was used to simulate and analyze regional climate characteristics of precipitation (Chen et al. 1999, Hong and Leetma 1999), low-level winds (Anderson et al. 2000; 2001; Anderson and Roads 2001), U.S. water and energy budgets (Roads and Chen 2000), and climate (Roads et al. 2002). The current model has also been used for dynamical downscaling from ECHAM3 seasonal climate prediction over Nordeste Brazil (Nobre et al. 2001), and global change scenarios over the U.S. (Han and Roads 2003), and eastern Asia (Chen 2001; Chen et al. 2002). This version of RSM was also used for the recent IRI/ARCS inter-comparison over South America (Roads et al. 2003).

The RSM is a regional extension of NCEP's global spectral model (GSM), the basic global model used for the NCEP/National Center for Atmospheric Research (NCAR) reanalysis (see Kalnay et al. 1996 for a description of the model physics). In particular, the RSM provides an almost seamless transition from the global GSM to the higher resolution region of interest and thus avoids a common regional model problem when using incompatible physics between the driving global model and the nested regional model (Chen 2001). Except for the scale-dependence built into the horizontal diffusion and some minor adjustment to other physical parameterizations, the GSM and RSM physical parameterizations are, in principle, identical. A modeling system such as the one used here is particularly helpful in isolating the regional downscaling problems caused by potential mismatched model physics between the regional and driving global model (Chen 2001). However, it should be noted that this version of RSM resembles more the GSM used for the subsequent NCEP/DOE reanalysis (Kanamitsu et al. 2002) than it does the driving NCEP/NCAR reanalysis I (RI; Kalnay et al. 1996). More discussion of the updated model physics can be found in Hong and Pan (1996), and more recently by Roads et al. (2002).

The RSM used for this study has the same 28 vertical sigma levels as the forcing reanalysis and uses the same primitive hydrostatic system of virtual temperature, humidity, surface pressure and mass continuity prognostic equations on terrain-following sigma coordinates as the GSM. A minor structural difference is that the GSM utilizes vorticity and divergence equations, whereas the RSM utilizes momentum equations in order to have simpler lateral boundary conditions. The GSM and RSM horizontal basis functions are also different. The GSM uses spherical harmonics with a triangular truncation of 62 (T62) whereas the RSM uses cosine or sine waves to represent regional perturbations about the imposed global scale base fields on the regional grids. Similar to the Gaussian grids used for the GSM, the regional grids are required for grid point transformation when nonlinear terms are to be computed. The double Fourier spectral representations are carefully chosen so that the normal wind perturbations are anti-symmetric about the lateral boundary. Other model scalar variables (i.e., virtual temperature, 
specific humidity, and surface log pressure) are symmetric perturbations. Finally, the RSM uses a Mercator projection while the GSM uses a Gaussian grid, and thus the geographical location of the grids do not match, requiring some interpolation from each grid. Therefore in the absence of any regional forcing, (and intrinsic internal dynamics and significant spatial resolution difference) the perturbations should be small and the total RSM solution should be almost identical to the GSM solutions.

\section{FORCING REANALYSIS AND OBSERVATIONS}

\subsection{Reanalysis I}

The 4 times daily NCEP/NCAR RI 28 vertical levels of virtual temperature, horizontal wind components, and specific humidity and surface pressure were used to force the RSM. All RI data are on triangular truncation 62 (T62) and roughly on $1.875^{\circ}$ Gaussian grids. Several auxiliary fields from the RI, including: sea surface temperatures, volumetric soil moisture, ground and soil temperatures, fractional cover of green vegetation, and sea-ice cover were used to initialize the RSM. Variables such as sea surface temperatures, vegetation cover, and sea-ice cover from RI were also used, on a daily basis, to update the regional model surface files during integration. Other prognostic surface variables were initialized from the reanalysis at the beginning of the continuous integrations. A refined surface interpolation (Chen et al. 1999; Roads and Chen 2000) was also employed to ensure proper interpolation of surface variables from global to regional grids.

\subsection{Observed Precipitation}

Xie and Arkin (1997) developed a global precipitation dataset at $2.5^{\circ}$ resolution that not only extends back to 1979 but also provides higher temporal resolution (pentads) over land and ocean. We used this $2.5^{\circ}$ data to force one of the experiments in this study as described in the next section. Xie (personal communication) subsequently developed an experimental daily $0.5^{\circ}$ resolution precipitation data set from gauges only over land regions, which became available to us after the simulation had been completed. As will be shown, this data set is highly correlated with the standard $2.5^{\circ}$ product and was finally chosen as the optimal data set for comparing the higher resolution RSM simulations.

\section{EXPERIMENT DESIGN}

\subsection{Experiments}

The simulation was done over an area from $85 \mathrm{~W}-20 \mathrm{~W}$ and $40 \mathrm{~S}-10 \mathrm{~N}$ with Mercator projection centered at $(15 \mathrm{~S}, 55 \mathrm{~W})$ and with $50-\mathrm{km}$ grid space. Figure 1 shows the evaluation domain, which covers the entire computational grids, less three grid points from each lateral boundary. The grid points indicate the land regions (separated between northern and southern South America at 15S), where the comparison was made for area average statistics. Model 


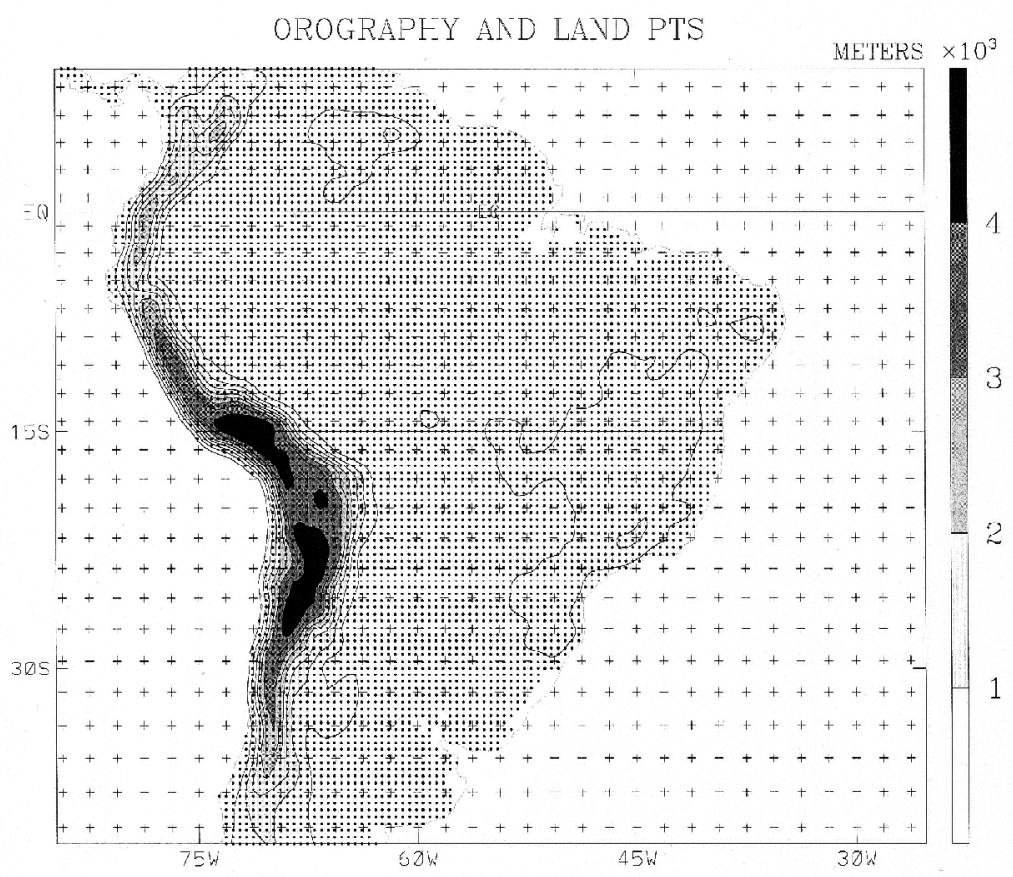

Fig. 1. Reanalysis grid points (+'s) over ocean and RSM grid points (50-km grid interval) over land for the evaluation domain. The map is a Mercator projection centered at $(15 \mathrm{~S}, 55 \mathrm{~W})$ and for reference the RSM orography is also shown. The $15 \mathrm{~S}$ longitude separates the evaluation land domain into Northern and Southern South America.

data was archived daily and we focused on the evaluation of precipitation for this study.

The RSM simulations were initialized on February 22, 1997 and the RSM was then run continuously through March 31, 1999, with evaluations beginning from March 1, 1997. Three simulations were developed. The first one ran the model in its original configuration (soil moisture uncorrected). As shown in Fig. 2, this uncorrected RSM simulation developed a severe surface moisture-dry bias, which affected the precipitation and other model variables. After one year, monthly-mean second layer (top 10 200 cm underneath surface) soil moisture SMC(2) (Fig. 2b) and precipitation (Fig. 2d) simulation demonstrated this drying effect especially when these months are contrasted with the initial month (Figs. 2a, c; see also the observed area mean precipitation in Fig. 3). Note especially the dryness in both soil moisture and precipitation over subtropical and Amazon regions. At the end of second year, the entire SMC (2) and tropical/subtropical precipitation (not shown) over land almost vanished, except coastal and mid-latitudinal regions where onshore flows or mid-latitudinal storms were dominant. This problem is perhaps not surprising since the NCEP GSM (e.g., Roads et al. 1999) is known to have a dry bias over many land regions, especially over South America. This bias is likely 


\section{UNCORRECTED}
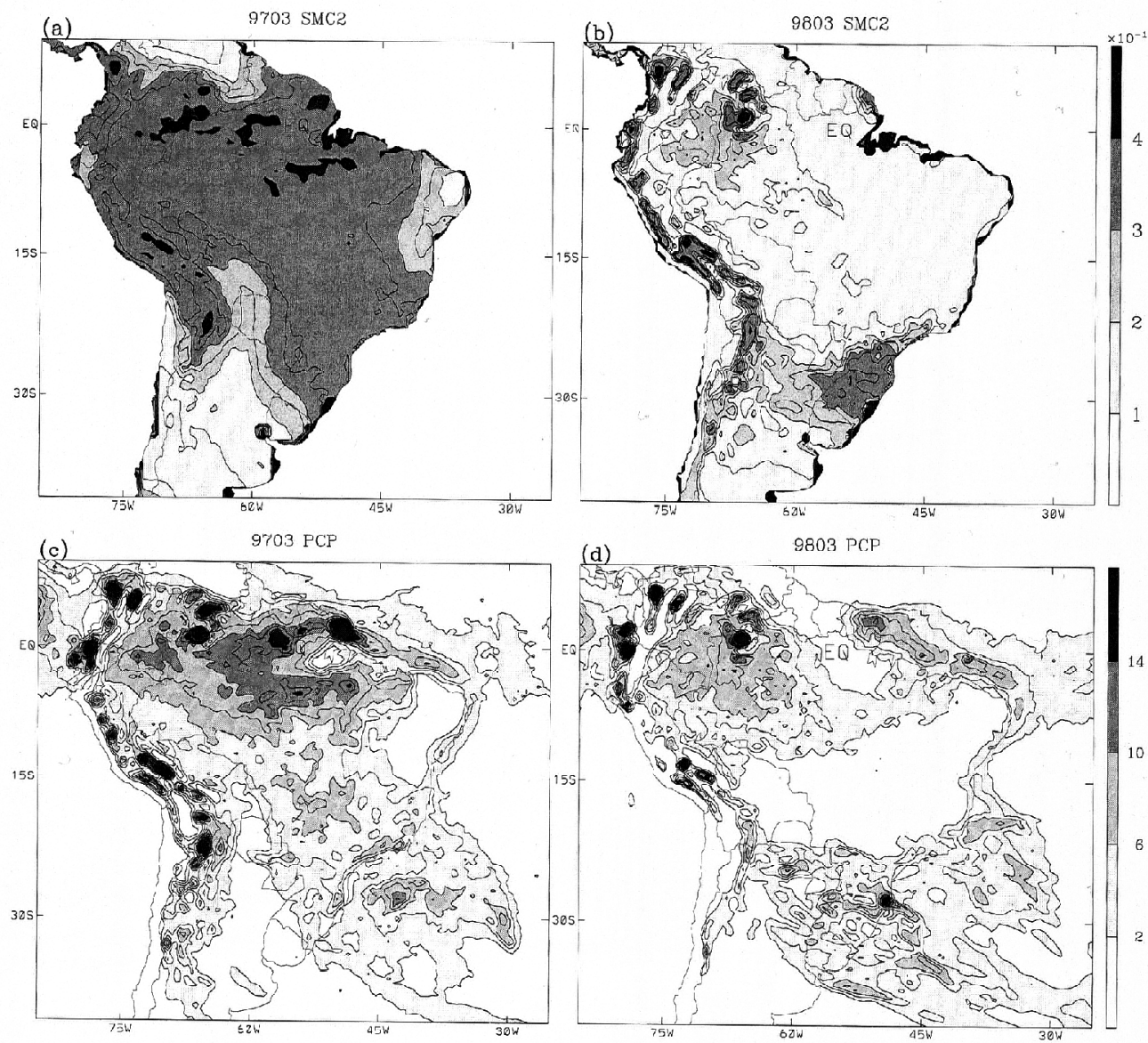

Fig. 2. RSM monthly-mean volumetric soil moisture content of the second layer for (a) March 1997 and (b) March 1998. The corresponding monthlymean precipitation in $\mathrm{mm} \mathrm{day}^{-1}$ are given in (c) and (d), respectively. Every two contour lines are shaded, and the shading intervals are given on the right panels.

due to the positive feedback among model precipitation, radiation and soil model. For example, insufficient precipitation leads to drier soil and lower cloud cover. The surface solar radiation then intensifies to further reduce the water-holding capacity of the soil and hence provides less recycling water back to the atmosphere. Again, since the RSM used the same physical parameterizations as GSM, it should not be too surprising that the RSM also suffered a similar drying problem over this area. 


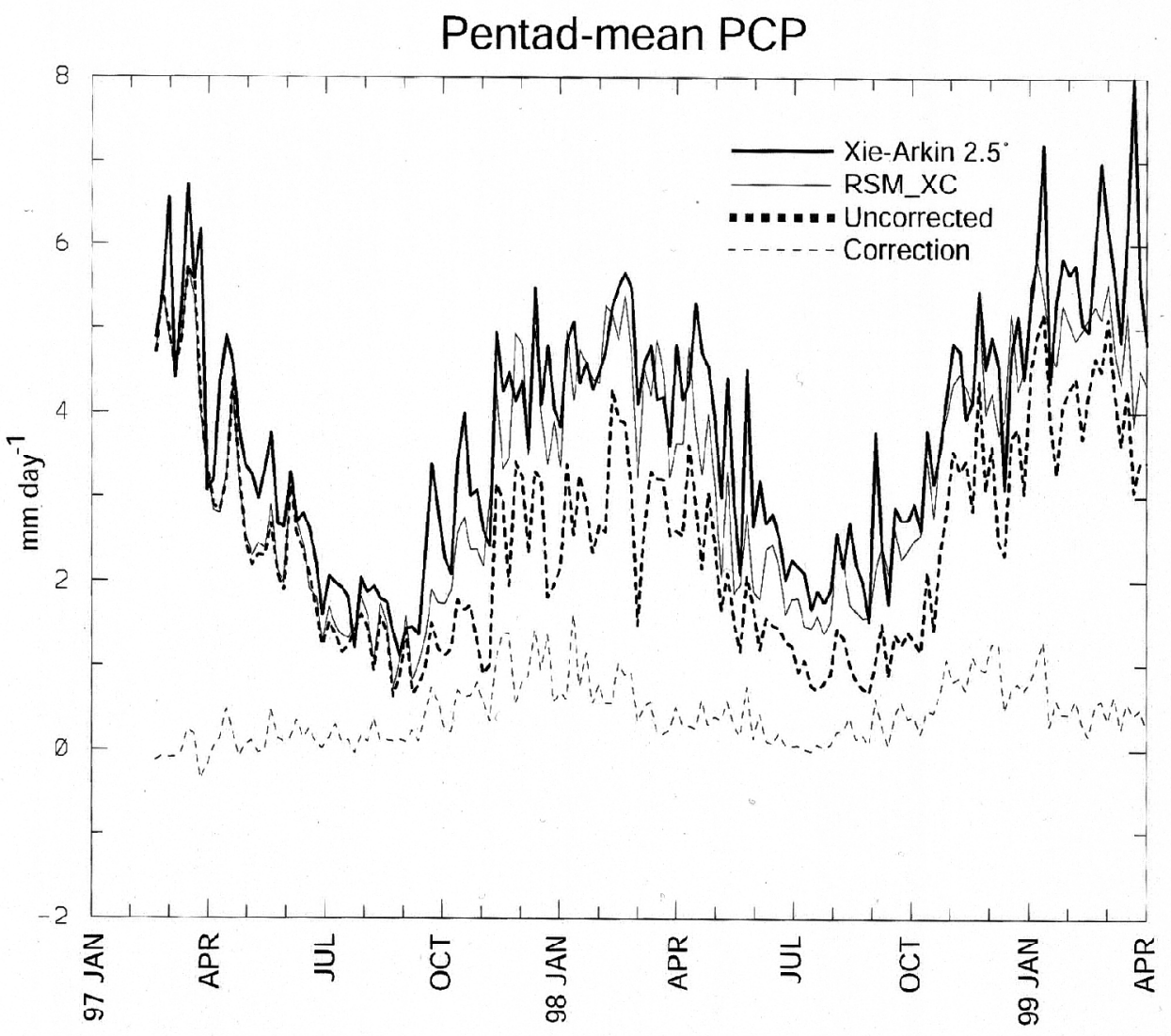

Fig. 3. Time series of pentad mean precipitation over the land region from $2.5^{\circ}$ Xie-Arkin, soil moisture content corrected RSM simulation (RSM_XC), the uncorrected run, and the amount of correction.

Our second and third experiments were designed to overcome this dry bias. The second experiment, RSM_RS hereafter, replaced RSM SMC(2) with that from the RI but allowed the model first soil layer (top $10 \mathrm{~cm}$ ), SMC(1), to fully interact with the overlaying atmosphere as well as the second soil layer. The update of the SMC(2) was done daily. A shorter period of this run was previously documented in Roads et al. (2003) as part of the multi-model intercomparison over the same region. As was previously shown in Roads et al. (2003), the RSM simulation produced precipitation comparable to other regional models but only marginally better than that of large-scale reanalysis when compared to observations.

The third experiment RSM_XC used, instead of reanalysis soil moisture, the observed $2.5^{\circ}$ Xie-Arkin precipitation data to correct the SMC(2). In the RI, the NCEP soil moisture drying was corrected by relaxing the model SMC values back to a climatology with a characteristic time scale of six months (Roads et al. 1999). There were a number of problems with 
this type of approach and subsequently a different method was developed for the NCEP/DOE Reanalysis II (RII; Kanamitsu et al. 2002). The RII used observed $2.5^{\circ}$ precipitation to correct the upper level soil moisture resulting from erroneous model precipitation. In this study we adopted the general philosophy of RII although the methodology was somewhat modified. Here we corrected only the lower level soil (lowest $190 \mathrm{~cm}$ ) moisture, SMC(2), and allowed the upper level (upper $10 \mathrm{~cm}$ ) soil moisture, $\mathrm{SMC}(1)$, to come to equilibrium with the model precipitation and the underlying SMC(2). The main reason we chose to do so is that the RSM produced higher resolution features than the driving coarse RI circulation; therefore, we felt that low spatial resolution tempering of the soil moisture in the first layer would be undesirable. Again, when we began these experiments, only low-resolution precipitation data were available. In fact, the soil moisture correction in RII is similar to our method, since when the top layer was saturated, the correction in RII was applied to the second layer, $\mathrm{SMC}(2)$ ), as well (Kanamitsu et al. 2002).

In detail, we adjusted the SMC(2) every 5 days using the differences between the pentad mean of $2.5^{\circ} \mathrm{Xie}$-Arkin precipitation and the accumulated model precipitation aggregated to the similar horizontal scale of the observations. We first ran the pentad-mean model precipitation through a 25-point spatial smoother to match the resolution of both precipitation fields. The spatial smoothing was important since (unlike the RII) our regional high-resolution precipitation and land surface were not well matched to the coarser global scale observations. Also the pentad accumulation and the spatial smoothing produced a slowly varying and broadscale correction of soil moisture at the second layer. Then we injected the required (when observation was more than model rain) water into the second layer only if the soil moisture content was dryer than the first layer, and water extraction was done if the model rain was in excess of observation and SMC(2) was wetter than SMC(1). These conditional injections and extractions were needed to prevent artificial over-saturation or overdraft of SMC(2). Preliminary experiments showed that some areas became fully desiccated or saturated if the conditional correction was not enforced. Any excess water from the SMC(2) after the correction was temporarily moved into the first layer, and runoff would then occur at the next time-step by the model surface hydrologic process. Occasions when this over-saturation of the second layer occurred were rather rare (10 times at 3 grid points throughout the entire two years of simulation). This correction scheme retained the interaction among the soil layers and the atmosphere for surface evaporation, evapotranspiration and infiltration processes in the model soil module (Pan and Mahrt 1987). Note that this correction, although similar to that used in RII, is rather artificial. Our purpose is to raise the level of the inter-annual differences of the surface forcing. Since there is no reliable observed soil moisture with desired spatial and temporal coverage, using the observed precipitation in conjunction with this rather artificial correction scheme might be the best available method we can use to test the sensitivity of the soil moisture to the simulation.

The correction was relatively small at each pentad interval (less than $5 \%$ in general) during rainy seasons in comparison to the model total rainfall; however, the impact was substantial. Figure 3 shows the simulated area average pentad-mean precipitation for the entire land region of South America. The uncorrected run (heavy dashed line) started to dry after about 6 months into the integration, consistent with the characteristic time scale of soil moisture depleting 
estimated in Roads et al. (1999). As expected, the RSM_XC run (solid thin line) stayed close to the uncorrected simulation for the first 6 months or so, then the two runs diverged, and the dry bias was corrected in the RSM_XC simulation. It is also encouraging to note that the wet bias of the RI precipitation (as shown in the area mean in Table 1) was improved in this RSM_XC simulation, however there were still some simulation defects. The RSM_XC pre-

Table 1. Temporal and area averaged precipitation for mean (Mean, $\mathrm{mm} \mathrm{day}^{-1}$ ), systematic error (SE, mm day ${ }^{-1}$ ), standard deviation (Std., $\mathrm{mm} \mathrm{day}^{-1}$ ), correlation (Corr.), area-mean normalized anomaly covariance (ACOV), standard deviation of ACOV time series (Std. ACOV).

\begin{tabular}{|l|c|c|c|c|c|c|}
\hline S. S. America & Mean & SE & Std. & Corr. & $\begin{array}{c}\text { Norm. } \\
\text { ACOV }\end{array}$ & $\begin{array}{c}\text { Std. } \\
\text { ACOV }\end{array}$ \\
\hline Xie0.5 & 2.76 & & 1.84 & & & \\
\hline Xie2.5 & 2.94 & 0.18 & 1.48 & 0.81 & 0.84 & 0.08 \\
\hline Reanalysis & 3.23 & 0.47 & 1.40 & 0.53 & 0.46 & 0.22 \\
\hline RSM_RS & 2.72 & -0.04 & 1.92 & 0.40 & 0.36 & 0.18 \\
\hline RSM_XC & 2.60 & -0.16 & 1.59 & 0.43 & 0.41 & 0.20 \\
\hline
\end{tabular}

\begin{tabular}{|l|c|c|c|c|c|c|}
\hline N. S. America & Mean & SE & Std. & Corr. & $\begin{array}{c}\text { Norm. } \\
\text { ACOV }\end{array}$ & $\begin{array}{c}\text { Std. } \\
\text { ACOV }\end{array}$ \\
\hline Xie0.5 & 4.18 & & 2.18 & & & \\
\hline Xie2.5 & 4.26 & 0.08 & 1,74 & 0.82 & 0.77 & 0.08 \\
\hline Reanalysis & 5.73 & 1.55 & 1.71 & 0.48 & 0.33 & 0.24 \\
\hline RSM_RS & 4.02 & -0.16 & 1.80 & 0.37 & 0.24 & 0.17 \\
\hline RSM_XC & 3.71 & -0.47 & 1.44 & 0.43 & 0.34 & 0.17 \\
\hline
\end{tabular}

\begin{tabular}{|l|c|c|c|c|c|c|}
\hline S. America & Mean & SE & Std. & Corr. & $\begin{array}{c}\text { Norm. } \\
\text { ACOV }\end{array}$ & $\begin{array}{c}\text { Std. } \\
\text { ACOV }\end{array}$ \\
\hline Xie0.5 & 3.56 & & 2.03 & & & \\
\hline Xie2.5 & 3.68 & 0.12 & 1.63 & 0.81 & 0.80 & 0.06 \\
\hline Reanalysis & 4.64 & 1.08 & 1.58 & 0.50 & 0.39 & 0.17 \\
\hline RSM_RS & 3.45 & -0.11 & 1.85 & 0.39 & 0.29 & 0.15 \\
\hline RSM_XC & 3.22 & -0.34 & 1.51 & 0.43 & 0.37 & 0.16 \\
\hline
\end{tabular}

* This manuscript was in part written and prepared by a U.S. Government employee on official time and therefore is in the public domain and not subject to copyright. 
cipitation was still a bit too dry compared to the observations (heavy solid line), despite the soil moisture correction, indicating potential problems with the model physics. However, it is beyond the scope of this paper to identify possible cause or causes of the model problematic precipitation, or any physical process which might lead to this defect. Instead this study only demonstrated the impact of the soil moisture on the precipitation simulation. The main contrast was between RSM_RS and RSM_XC precipitation experiments in comparison to that from reanalysis when validated against $0.5^{\circ}$ observations.

\subsection{Skill Measures}

In this study we used the objective tests previously described by Roads et al. (2002, 2003). All statistical evaluations were done over the land points shown in Fig. 1. Area mean and systematic error (SE; model minus observation) were first examined. The simulation skills of the models were then evaluated by anomaly standard deviation (STD) and temporal correlation. Computation of these statistics of anomaly was usually done by first removing long-term seasonal climatology. The exact procedure in constructing monthly anomaly was to subtract the 18-pentad running mean of the two-year climatology from the monthly 6-pentad running mean. However since we have only two full years of simulations, the derived "anomalies" were actually interannual differences. For the sake of brevity, hereafter we refer to this interannual difference as anomaly and the two-year averages of the corresponding running mean as "climatology". The anomalies of simulation and observation could then be used to compute temporal correlation over time, or time series of the spatially averaged anomaly covariance (ACOV) normalized by the respective standard deviation at each grid point. Furthermore, the significance of the time-average correlations could be measured by dividing the standard deviation of the normalized covariance by the square root of the number of independent observations. More detailed descriptions can be found in Roads et al. $(2002,2003)$.

NCEP equitable threat and bias scores (ETS) were also used here to further assess the precipitation skill for more intense precipitation (see Mesinger and Black 1992). The equitable threat score is defined as:

$$
E T=\frac{H-C H}{F+O-H-C H}
$$

where $F$ and $O$ are the number of forecast and observation points in the evaluation domain that have precipitation above a certain threshold. $H$ is the grid point number of correct forecast ("hit") above a threshold. $\mathrm{CH}$ is the expected number of hits in a random forecast of $F$ and observed $O$ and has the form:

$$
C H=\frac{F \times O}{N},
$$

where $\mathrm{N}$ is the total number of points over the evaluation domain. Basically, the threat score is 
scaled so that zero indicates random predictions and 1 indicates perfect forecasts. The bias score is the ratio of the forecast and observed points and is defined as:

$$
B L A S=\frac{F}{O} .
$$

A bias value above (below) 1 indicates a model wet (dry) bias. These scores were originally designed for weather forecast or evaluations where the total amount was the only concern. In particular the above formula also includes an evaluation of the climatology. However in climate studies, the variability is also of concern. We therefore redefined these measures by first removing the background climatology (seasonal cycle). The positive anomaly threshold was treated in the same way as the traditional definition, while for negative anomalies, $F, O$ and $H$ were defined as corresponding points where the relative dryness was greater than the threshold. We hereby denote these measures as anomaly equitable threat scores (aETS).

\section{RESULTS}

Figure 4 shows the March-April-May (MAM) 1998 precipitation of the RSM_RS and RSM_XC simulations in comparison to that from the RI along with observed $0.5^{\circ}$ gridded precipitation. During this period the South America Monsoon precipitation was still active over land, especially over the northeastern Amazon. A precipitation center over the southern tip of Brazil was another characteristic feature. Both RSM simulations improved the reanalysis precipitation features, in particular, they somewhat reduced the excess reanalysis precipitation over the northeastern Amazon Basin and over central Brazil. However the excess precipitation is still evident. As stated previously, and in Roads et al. (2003), our RSMs might have also inherited erroneous circulation from reanalysis as did other regional models. Unfortunately both RSM simulations overcorrected the reanalysis wet bias over subtropical Brazil. The mid-latitude precipitation center was also slightly displaced southwestward. Another questionable feature was the minor precipitation center over the Andes. There was almost no precipitation over this region in the observations, whereas a narrow rain band aligned with the Andes in the reanalysis and in both RSM simulations. Although we have previously noted spurious excess rainfall in the models with sigma coordinates over mountainous region (Chen et al. 1999; Roads et al. 2002), the lack of rain over the Andes in the observations still seems somewhat suspicious.

Despite systematic biases in model simulations, interannual variation may not actually be influenced. For example, Figure 5 shows the contrast between MAM 1998 and 1997. These years represent the difference between the weak La Niña episode in 1997 and the strong El Niño in 1998. There is a typical wet/dry dipole structure over northeastern and southern Brazil. The wet anomaly over western and central Brazil is associated with strong cyclonic moisture fluxes. Both RSM simulations inherited and followed the large-scale interannual dipole patterns in RI closely but with some regional modifications. As in the reanalysis, the dipole structure was displaced somewhat to the south of the observations. However, the simu- 

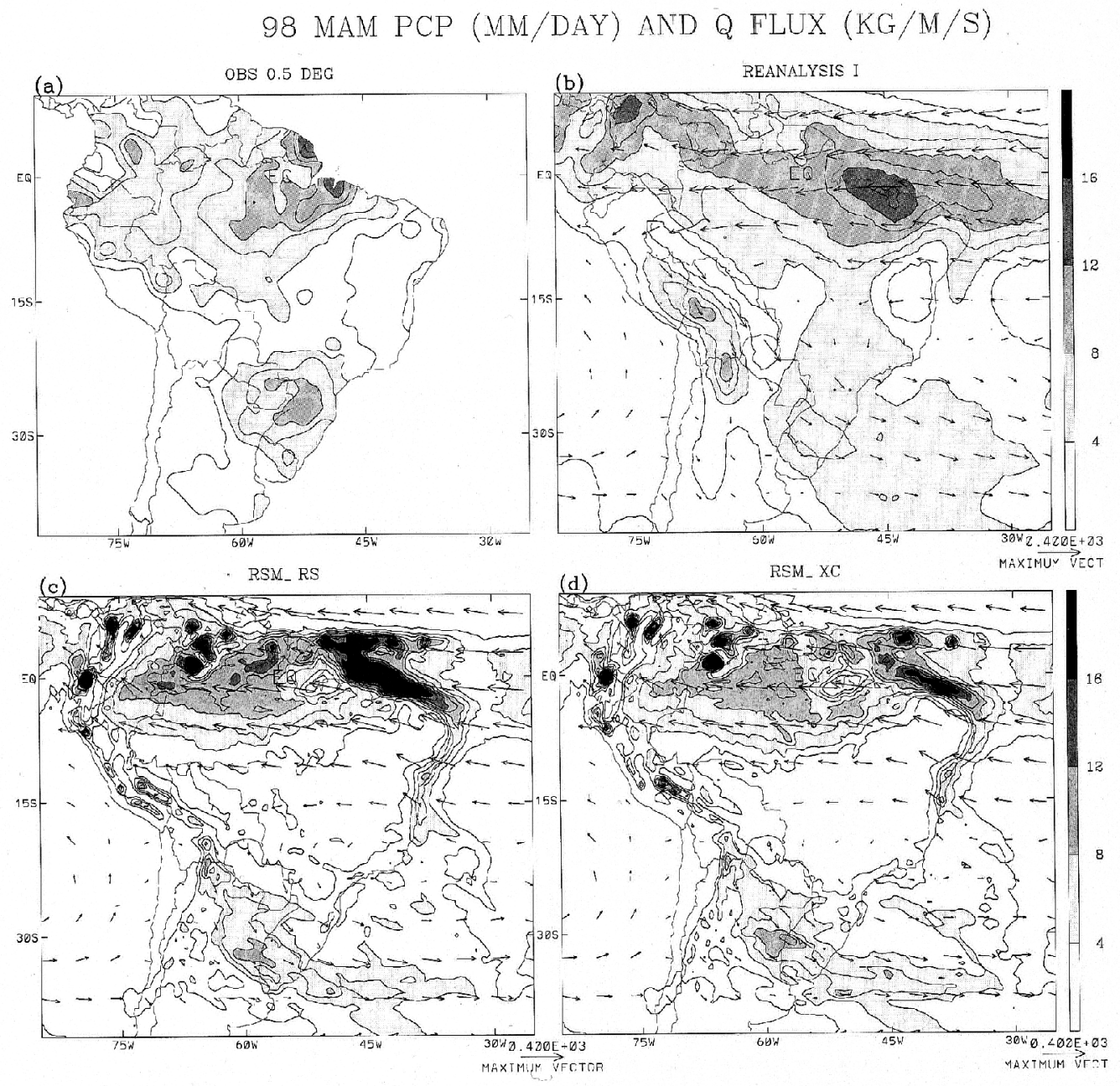

Fig. 4. MAM 1998 seasonal mean precipitation and vertically integrated moisture fluxes for (a) observed; (b) reanalysis I (RI); (c) RI SMC(2) specified RSM run (RSM_RS); (d) interactively corrected RSM run (RSM_XC). Precipitation contours are in $\mathrm{mm} \mathrm{day}^{-1}$, and every two contours are shaded; the scale vector of moisture flux in $\mathrm{Kg} \mathrm{m}^{-1} \mathrm{~s}^{-1}$ is shown at the lower right corner of each panel.

lation of the dipole amplitudes were somewhat improved in both RSM runs, especially in the extra-tropical region where the dry region was amplified in comparison to the observations, from a rather weak response in the reanalysis. Note that the unrealistic dryness over northeastern Brazil in the reanalysis was reduced somewhat in the RSM simulations. 


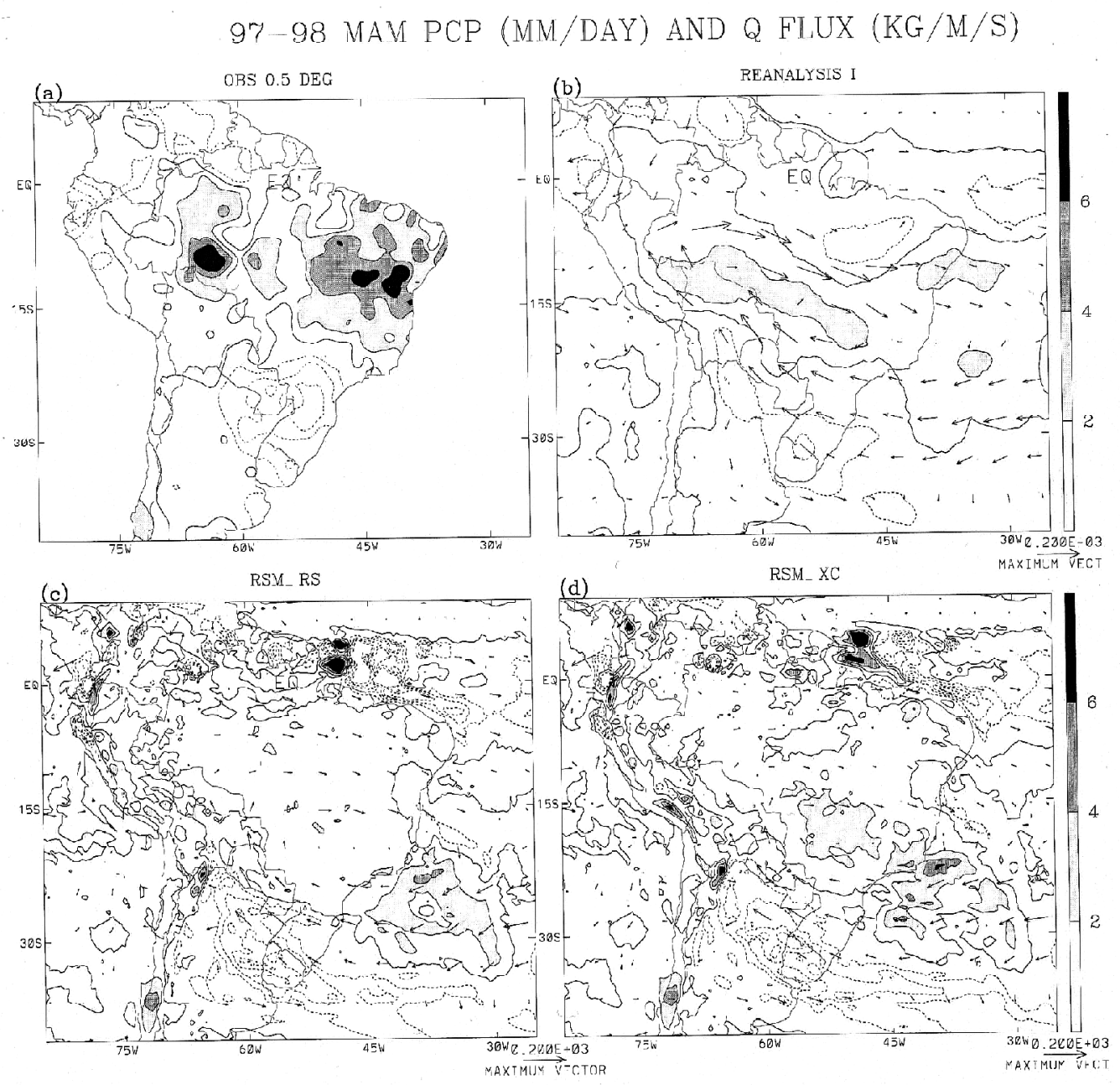

Fig. 5. Same as Fig. 4, except for the interannual seasonal mean difference of 1997 MAM minus 1998 MAM. Contour and shading intervals are $2 \mathrm{~mm} \mathrm{day}^{-1}$. Negative contours are in dashed line. The scale vector of moisture flux is $200 \mathrm{Kg} \mathrm{m}^{-1} \mathrm{~s}^{-1}$.

Mean differences between the two RSM simulations were subtle, except perhaps for the enhanced wet anomaly over central Brazil. Skill differences among the reanalysis, RSM_RS and RSM_XC, however, could be detected from objective statistics. The spatial averaged statistics in monthly mean time series are shown in Fig. 6. Note that the mean values of the time series are the same as those corresponding terms in Table 1 . Here, monthly means were defined as a 5-pentad running mean. The area average of observed, RI, RSM_RS and RSM_XC 


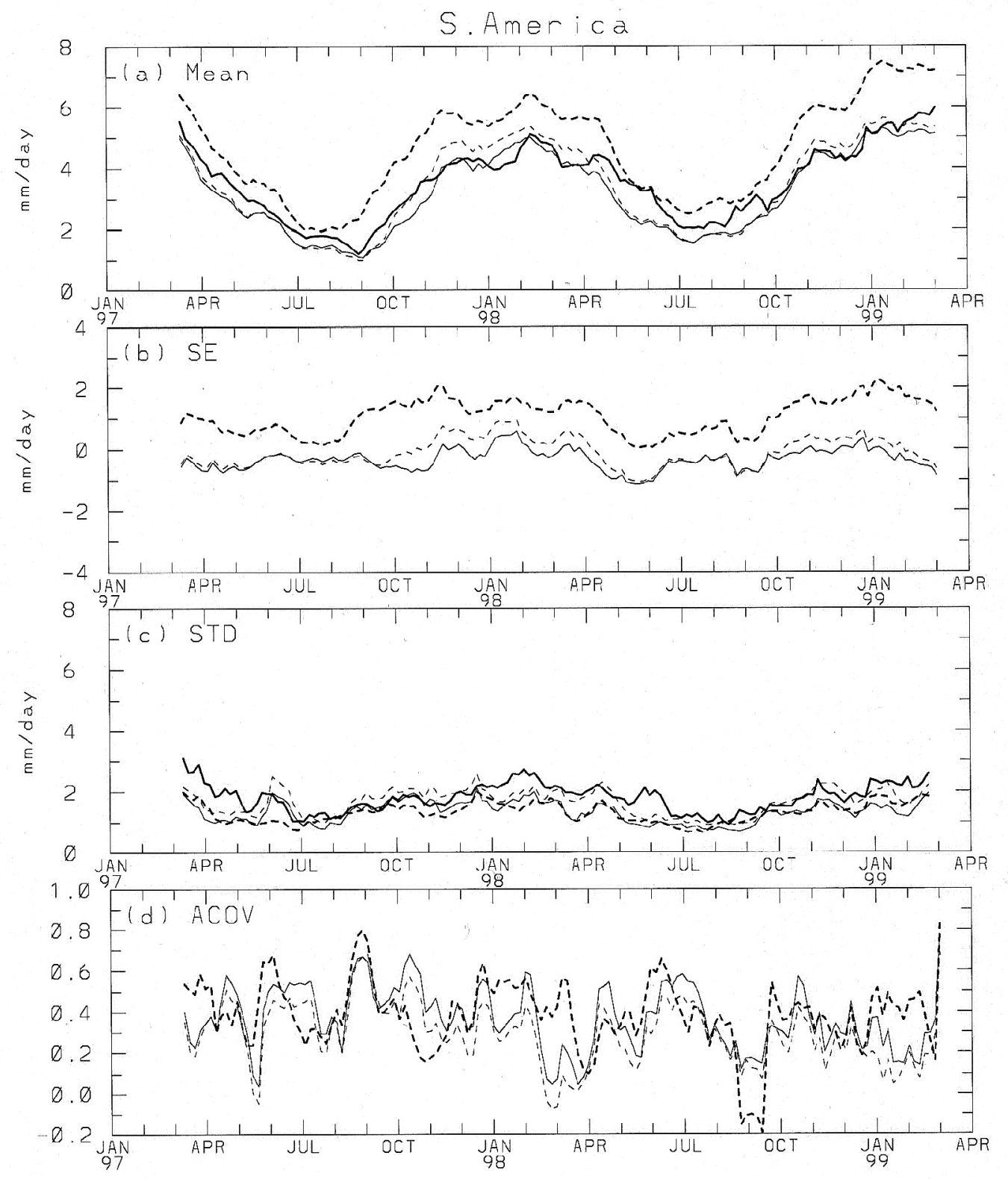

Fig. 6. Monthly area averaged time series (Mar. 1997 - Mar. 1999) evaluated over entire land area for observations (thick solid line), reanalysis I (thick dashed line), RSM_RS (thin dashed line) and RSM_XC (thin solid lines): (a) area means, $\mathrm{mm}^{-} \mathrm{day}^{-1}$; (b) systematic error, $\mathrm{SE}, \mathrm{mm} \mathrm{day}^{-1}$; (c) standard deviation, STD, mm day ${ }^{-1}$; (d) normalized covariance, ACOV. 
precipitation over the entire land area is shown in Fig. 6a. Strong annual cycle in all data sets was revealed. However, the analysis had an overall positive systematic error, which was corrected in both RSM runs (Fig. 6b). Unfortunately as shown in Table 1, RSM_XC overcorrected this bias and the simulation had a somewhat dry bias. The area averaged standard deviation of the anomalies (with seasonal climatology removed) in Fig. 6c indicates there were slightly underestimated amplitudes of variation for both models, but particularly for RI, as also shown in the time and area mean in Table 1. However, normalized covariance (Fig. 6d) reveals large variation in the simulation skill. There were times the RSM simulations seemed to significantly improve the available skill from reanalysis (e.g., September 1998), but there were also times the RSM simulations degraded the analysis (e.g., March 1998). Over the entire period and land area, the area-mean ACOV of RSM_XC simulation was statistically indistinguishable from the reanalysis (Table 1). For roughly 12 independent samples and the given standard deviations of ACOV in Table 1, the difference in ACOV should be about 0.06 or higher to be significant at 95\% confident level for an one-sided two-sample t-test. The extra tropical regions of South America (S. S. America) were probably the only regions for which RSM_XC simulation was not statistically better than RSM_RS. The superiority of the RSM_XC simulation over RSM_RS was demonstrated mostly in northern South America. This can be seen from the time series in Fig. 7d as the ACOV of RSM_XC simulation was constantly above that of the RSM_RS simulation. However, other statistics were similar to the all-land area averages. Both RSM simulations certainly countered the wet bias of the reanalysis, except the SE in Fig. 7b indicates that the RSM_XC simulation might have overcorrected the RI wet bias.

Figure 8 shows the temporal standard deviation of the monthly mean anomalous precipitation from the $0.5^{\circ}$ observations, RI, RSM_RS, and RSM_XC. Area mean values are provided in Table 1. Overall, reanalysis and RSM_XC had values somewhat smaller than the observations, particularly in tropical and subtropical South America. The comparable standard deviation of RSM_RS to observation was actually a balance of excess values in southern South America and deficient values in extra-tropical areas. When geographical patterns in Fig. 8 were examined, it was found that the excess values in the higher latitude regions were mainly contributed in the northern Argentina Plateau. This excessive variability over the steep mountain region is also evident in other regional models, including reanalysis, as shown in Roads et al (2002). The region with underestimated variability is mainly over the Nordeste where RSM simulations seemed to further reduce the variability from the relatively dry reanalysis.

Geographic correlation maps are shown in Fig. 9. The correlation with 2.5 data in Fig. 9a might be thought of as the maximum score for a coarse resolution model. It can also be used as a gauge of self-consistency for the observation data. Despite its low resolution, the 2.5-degree observations have very high temporal correlation with the high-resolution observations. Areas with correlation coefficients 0.3 or above are statistically significant at the $95 \%$ confidence level for all maps in Fig. 9. For South America, the correlation is low only for the area over northern Chile (foothills of the Andes) where it is in proximity to the low precipitation area in Fig. 4a. Basically, reanalysis shows reasonable skill over all areas, except over northern Peru and Colombia, Bolivian Altiplano, and northeast Brazil. The RSM simulations did improve the correlations from reanalysis over these regions. However, the RSM skill deteriorated over 


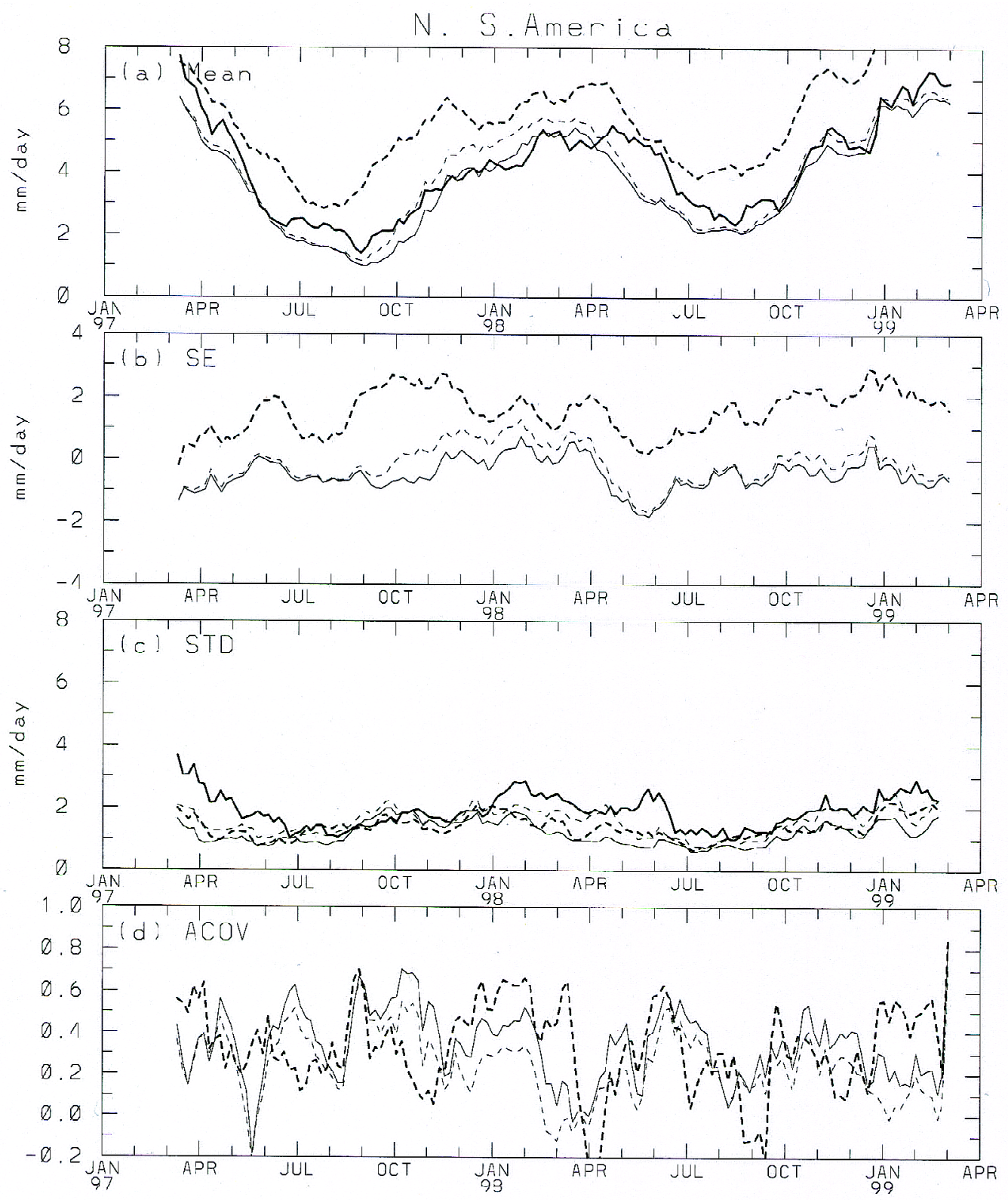

Fig. 7. Same as Fig. 6, except for land area north of $15^{\circ}$ S.

the Nordeste and eastern South America. As a result, the area-mean model ACOV, and hence correlation (Table 1) showed little improvement from the RI. Given the results from Fig. 9a, it is perhaps not too surprising to find limited overall improvement from either high resolution RSM simulation. 

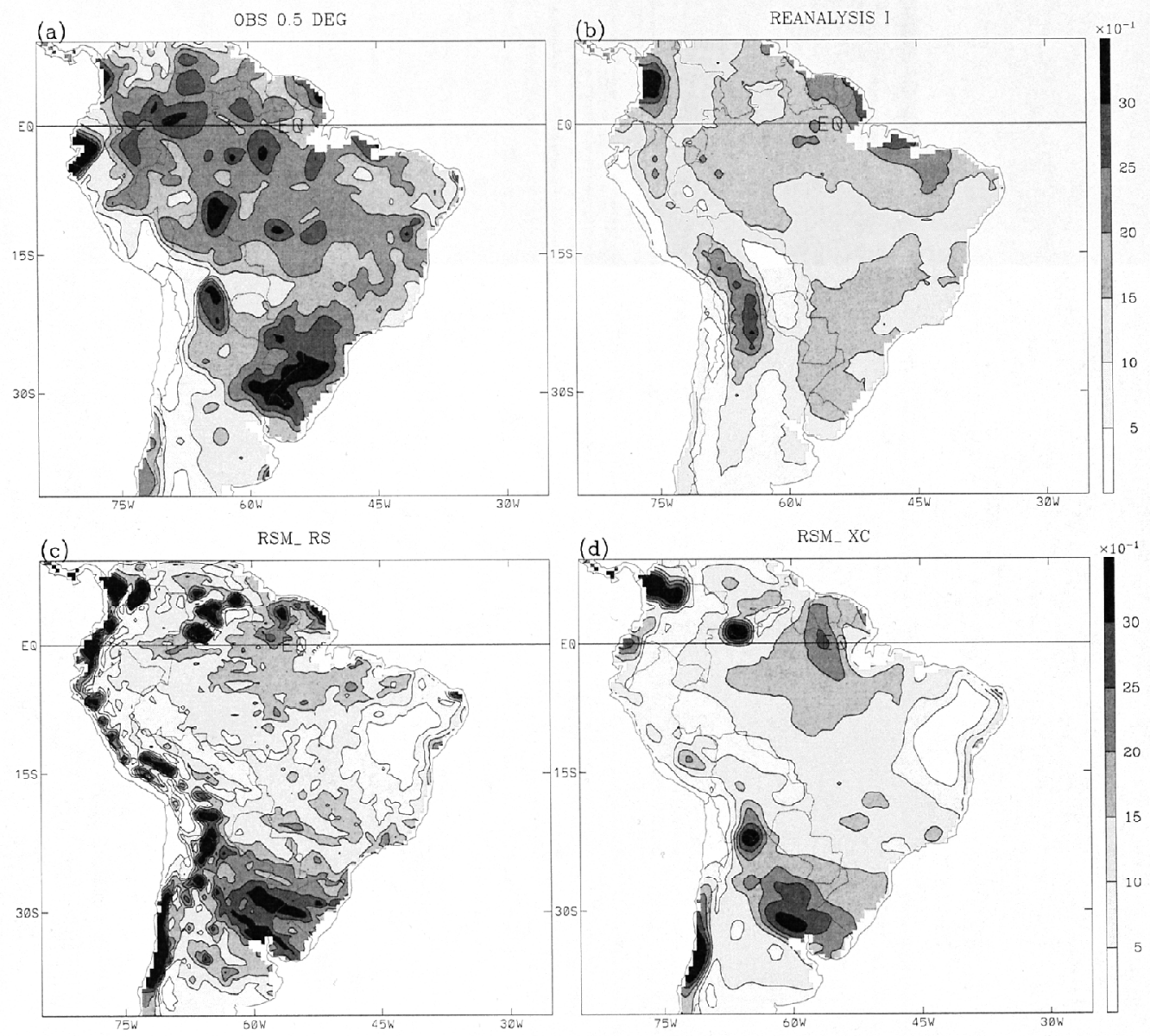

Fig. 8. Standard deviation for: (a) observations; (b) RI; (c) RSM_RS; (d) RSM_XC. Contour and shading intervals are $0.5 \mathrm{~mm} \mathrm{day}^{-1}$.

The monthly equitable threat score (ETS) and bias scores, frequently used by NCEP for synoptic event evaluation, were also examined (Figs. 10a, b). Although both RSM simulations improved the precipitation ETS and reduced the wet bias of the reanalysis over the moderate intensity range, the improvement was small. To investigate how robust this regional simulation was, an additional regional ensemble run of RSM_XC, starting from an initial condition one day after the original date, was also run. The analysis of this run is included in the plots as a separate thin solid line. As can be seen, characteristics of this additional run are barely distinguishable from the original reference RSM_XC run.

Since the traditional ETS evaluates model precipitation skill at total values, it is influ- 

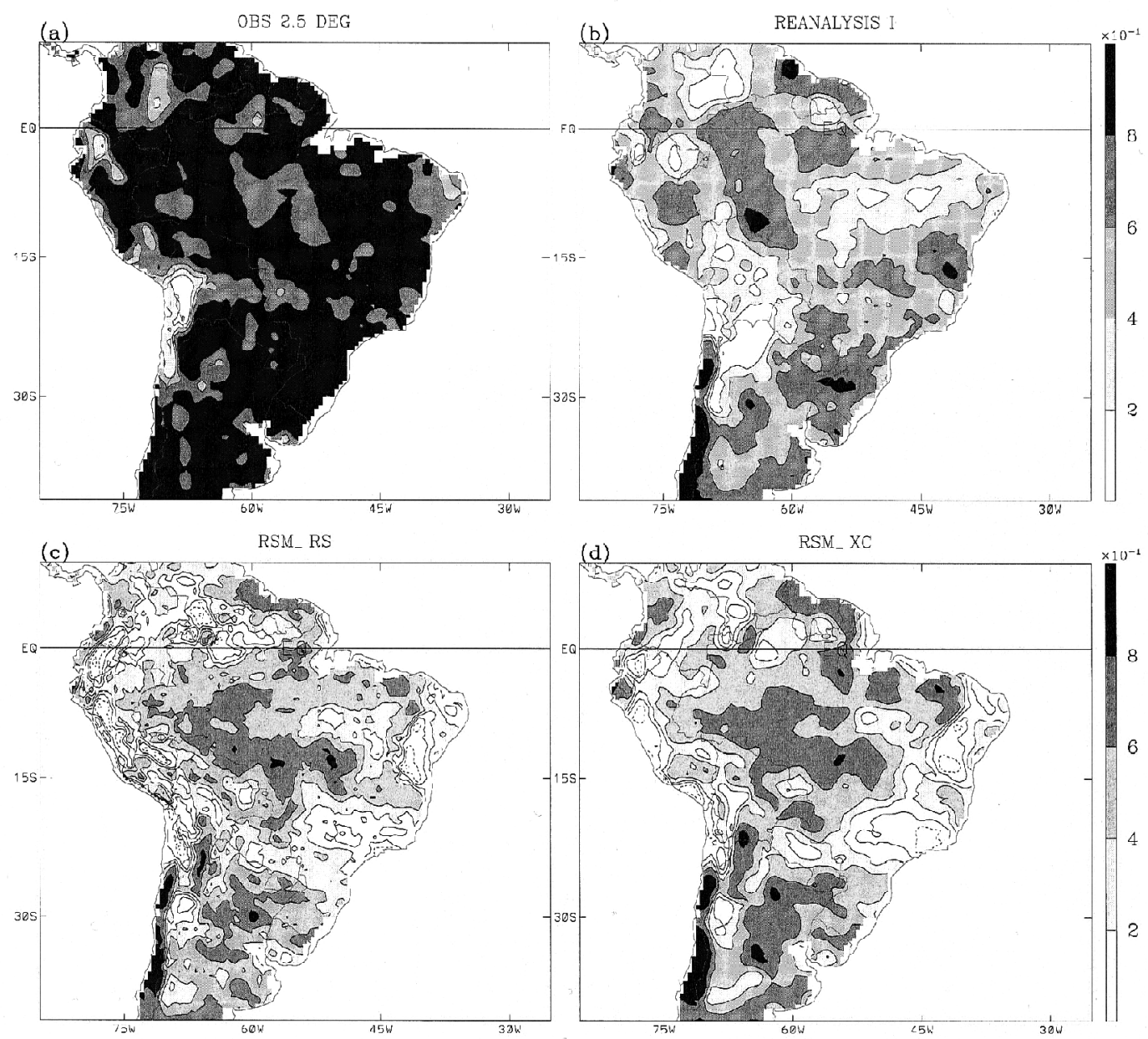

Fig. 9. Correlations between observations and (a) $2.5^{\circ}$ Xie and Arkin, (b) Reanalysis I, (c) RSM_RS, (d) RSM_XC. Contour and shading intervals are 0.2 . Areas with correlations less than 0.2 are not shaded, and the negative contours are dashed.

enced by the systematic biases in the climatology. We therefore removed the corresponding seasonal mean climatologies from the monthly mean time series and normalized the precipitation intensities by their corresponding temporal standard deviations at each grid point. A normalized anomaly threat score (aETS) was then defined as a value larger (smaller) than a positive (negative) multiple of standard deviation. The resulting aETS scores are shown in Figs. 10c, d. While the reanalysis was still better at weak precipitation events, this figure shows both RSM_XC ensemble runs were slightly higher than RI at a precipitation rates larger than two 
Monthly Mean
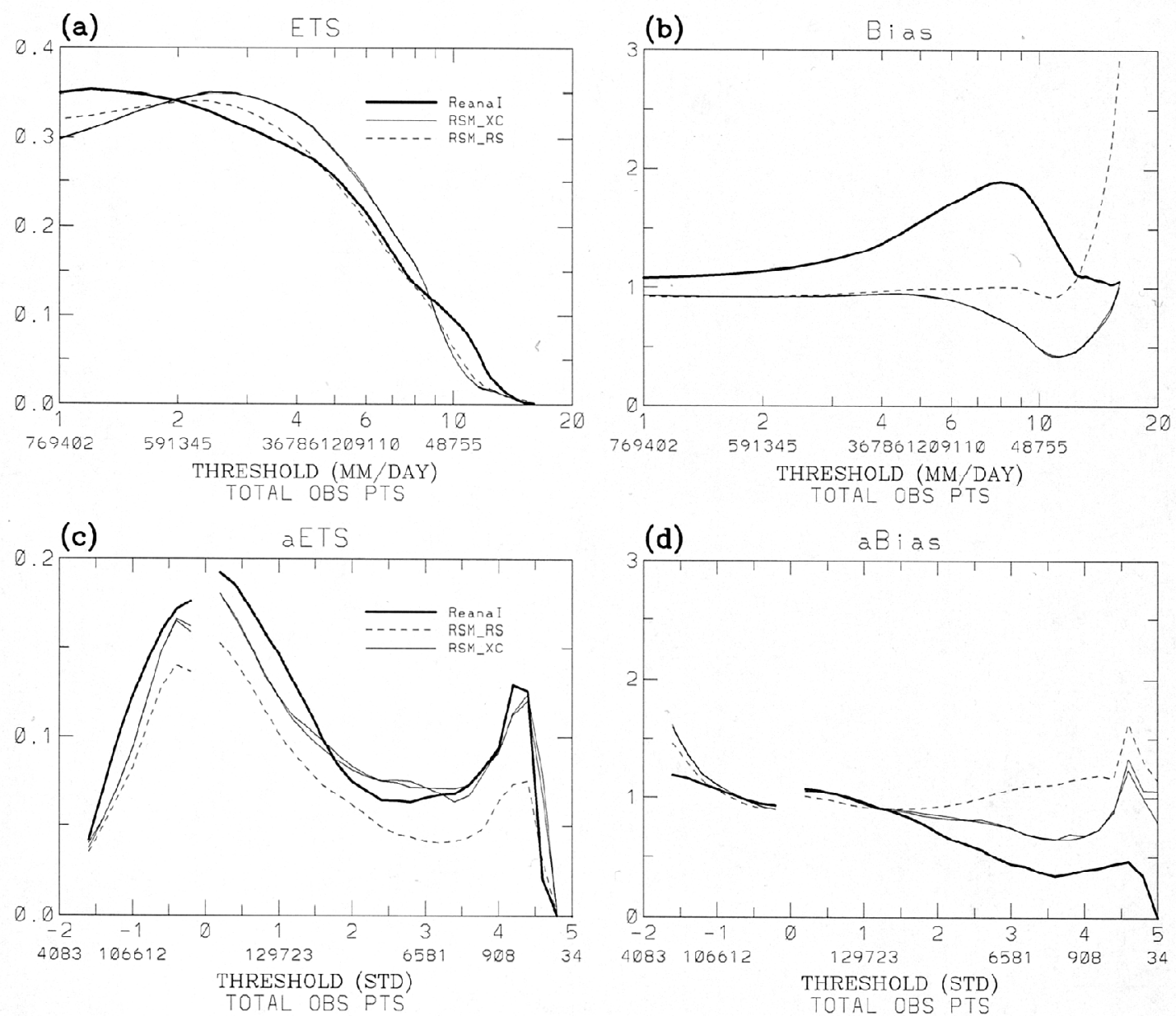

Fig. 10. Equitable threat and bias skill scores for precipitation for Reanalysis I (thick solid lines), RSM_RS (thin dashed lines) and RSM_XC (thin solid lines). Those from the second member of RSM_XC runs are also given by thin solid lines. The scores for total monthly mean are shown in (a) and (b), those for the anomalies after removing seasonal mean are shown in (c) and (d).

standard deviations. Again, these two ensemble runs were statistically undistinguishable. It is also interesting to see that the driving RI provided enhanced skill for normalized extreme precipitation intensity ranges larger than three standard deviations, and consequently provided a similar increase for both RSM simulations. Also note that throughout the entire ranges, both 
members of the RSM_XC experiment outperformed RSM_RS. The anomaly bias scores also revealed encouraging improvements from the RSM simulations. Note that the RSM corrected the overall wet bias of reanalysis and enhanced the normalized variation. This improvement was particularly evident for wet anomalies. Unfortunately none of the simulations showed any additional skill in defining dry events, especially for those events more intense than one standard deviation.

\section{SUMMARY AND DISCUSSION}

A known soil moisture dry bias in NCEP global models over S.A. and its impact on precipitation still exists in the RSM. If the problem is left uncorrected, the soil moisture in the deep layer can become completely dry, subsequently reducing the evaporation and ultimately the precipitation. This desiccation is particularly severe over tropical and subtropical South America.

Using the observed precipitation to force the deep layer, we provided an interactive empirical method (RSM_XC) capable of retaining the soil moisture in the deep layer (second layer) at a reasonable level and distribution, which then ultimately produced more realistic precipitation amounts and patterns. The correction was rather small in comparison to the total precipitation, however the effect was significant. In a parallel experiment (RSM_RS) we specified the soil moisture in the second layer with values from reanalysis I, which also proved to be a useful fix as demonstrated in Roads et al. (2003). By comparing the simulation skill of these two experiments to observed high resolution $0.5^{\circ}$ precipitation data, we emphasized the importance of the soil moisture in influencing the precipitation of this region.

In terms of the interannual contrasts there were only small differences in RSM precipitation patterns when compared to the available observations. Although both the RSM_RS and RSM_XC simulations revealed an amplified dry anomaly from reanalysis in 1997 over southern Brazil, the RSM_XC simulation emulated the South America subtropical wet region only slightly better than RSM_RS. Both RSM simulations underestimated the observed wet anomaly over Nordeste. While both RSM simulations corrected the overall precipitation wet bias in reanalysis, similar to other regional models (Roads et al. 2003), it is still difficult to conclude that RSM simulations contributed additional high-resolution information to the reanalysis precipitation field. Neither temporal ACOV nor pattern correlation showed any major advantage in using a regional model to improve the coarse reanalysis in producing high-resolution precipitation.

However, while spatial and temporal correlations failed to show the advantage of using regional climate model in this area, the monthly-mean equitable threat (ETS) and bias did demonstrate some skill from the RSMs, again in the improvement of the overall wet bias correction from the reanalysis precipitation. However, biases in the climatology, and hence the climatological influence on the ETS, may not adequately reflect the true skill for climate anomalies. A normalized anomaly equitable threat score (aETS) was therefore proposed where all values at each grid point were normalized by their respective temporal standard deviations after the seasonal climatology was removed. The aETS indicated that the RSM_XC simula- 
tion provided only, at best, similar skills as the observing reanalysis, although the low bias at the extreme high intensity was actually improved over the reanalysis. The interactive RSM_XC simulations, however, were consistently better than the RSM_RS simulation.

In summary, we found a soil moisture correction was needed to counter the dry bias of NCEP models over South America. In principle, this correction could use either the reanalysis I deep soil moisture, or a deep soil moisture corrected by differences from observed and simulated precipitation, and the latter correction did provide a somewhat better simulation. Since the soil moisture in reanalysis lacks low frequency variability (Roads et al. 1999), it is not clear from these experiments if the improvement was due to better temporal variation or better horizontal distribution of soil moisture in RSM XC. However, since there is no reliable observed soil moisture available over this region, it is difficult to evaluate how relatively realistic these two soil moisture distributions are. It should also be noted that the soil moisture nudging we used in this study is at best a remedy to counter the dry bias in the climate integration of RSM. Due to the complicated interactions among modeled radiation, soil physics and precipitation mechanism, these experiments do not indicate, exactly, why this drying defect occurred. However, understanding the atmospheric responses to these surface boundary characteristics is critical in interpreting simulation results from future development and for implementation of surface models in this model (e.g., Misra et al. 2001). This correction method might also have an application value. If the current RSM is driven by a global model free of dry bias over this region for simulations or climate forecasts, the precipitation from the global model can be used in conjunction with the method proposed in order to prevent the RSM from drying extensively.

Finally, now that we have high-resolution precipitation observations, it would be of interest to examine the simulation skill if the high-resolution upper layer were to be directly modified as in reanalysis II, or if an ensemble of short-term (1-day) forecasts is actually better than the continuous simulation as demonstrated in Roads et al. (2002) over the United States. Such experiments are currently underway.

Acknowledgements This research was funded by a cooperative agreement from NOAANA77RJ0453 and NOAA-NA17RJ1231 for Experimental Climate Prediction Center at Scripps Institution of Oceanography. The views expressed herein are those of the authors and do not necessarily reflect the views of NOAA. We thank M. Kanamitsu for his insightful comments on this research. The anonymous reviews were also quite helpful in improving the presentation of these results.

\section{REFERENCES}

Anderson, B. T., J. Roads, S. Chen, and H. M. Juang, 2000: Regional modeling of the lowlevel monsoon winds over the Gulf of California and Southwest United States: Simulation and validation. J. Geophys. Res. Atmos., 105, 17955-17969.

Anderson, B. T., and J. O. Roads, 2001: Summertime moisture divergence over the southwestern US and northwestern Mexico. Geophys. Res. Lett., 28, 1973-1976. 
Anderson, B. T., J. O. Roads, S. C. Chen, and H. M. H. Juang, 2001: Model dynamics of summertime low-level jets over Northwest Mexico.J. Geophys. Res. Atmos., 106, 34013413.

Bosilovich, M. G., and W. Y. Sun, 1999: Numerical simulation of the 1993 Midwestern flood: Land-atmosphere interactions. J. Climate, 12, 1490-1505.

Chen, S. C., J. O. Roads, and H. M. H. Juang, M. Kanamitsu, 1999: Global to regional simulations of California wintertime precipitation. J. Geophys. Res. Atmos., 104, 3151731532.

Chen, S. C., 2001: Model mismatch between global and regional simulation. Geophys. Res. Lett., 29, 4.1-4.4.

Chen, S. C., M. C. Wu, S. Marshall, H. M. H. Juang, and J. O. Roads, 2002: 2xCO, Eastern Asia Regional Responses in the RSM/CCM3 Modeling System. Global Planet. Change, 37, 277-285, doi: 10.1016/S0921-8181(02)00199-6.

Chou, S. C., A. M. O. Nunes, and I. F. A. Cavalcanti, 2000: Extended range forecasts over South America using the regional eta model. J. Geophys. Res. Atmos., 105, 1014710160.

Giorgi, F., L. Mearns, C. Shields, and L. Mayer, 1996: A regional model study of the importance of local versus remote controls of the 1988 drought and 1993 flood over the central United States. J. Climate, 9, 1150-1168.

Giorgi, F., B Hewitson, J. Christensen, M. Hulme, H. von Storch, P. Whetton, R. Jones, L. Mearns, and C. Fu, 2001: Regional climate information - Evaluation and projections. Climate Change 2001: The scientific Basis, Intergovernmental panel on Climate Change, Cambridge Univ. Press, $881 \mathrm{pp}$.

Han, J., and J. O. Roads, 2003: U.S. Climate Sensitivity Simulated with the NCEP Regional Spectral Model. Climate Change, 62, 115-154, doi:10.1023/B:CLIM.0000013675. 66917.15.

Hong, S. Y., and H. L. Pan, 1996: Nonlocal Boundary Layer Vertical Diffusion in a Medium Range Forecast Model. Mon. Wea. Rev., 124, 2322-2339.

Hong, S. Y., and A. Leetma, 1999: An Evaluation of the NCEP RSM for regional climate modeling. J. Climate, 12, 592-609.

Juang, H. M. H., and M. Kanamitsu, 1994: The NMC nested regional spectral model.Mon. Wea. Rev., 122, 3-26.

Juang, H., S. Hong, and M. Kanamitsu, 1997: The NMC nested regional spectral model. An update. Bull. Am. Meteor. Soc., 78, 2125-2143.

Kalnay, E., M. and colleagues, 1996: The NCEP/NCAR 40-year Reanalysis project. Bull. Am. Meteor. Soc., 77, 437-471.

Kanamitsu, M., W. Ebisuzaki, J. Woollen, S. K. Yang, J. J. Hnilo, M. Fiorino, and J. Potter, 2002: NCEP-DOE AMIP-II Reanalysis (R2). Bull. Am. Meteor. Soc., 83, 1631-1643.

Kanamitsu, M., and K. C. Mo, 2003: Dynamical effect of land surface processes on summer precipitation over the Southwestern United States. J. Climate, 16, 496-509.

Kim, J., N. L. Miller, J. D. Farrara, and S. Y. Hong, 2000: A seasonal precipitation and stream flow hindcast and prediction study in the Western United States during the 1997/98 winter season using a dynamic downscaling system. J. Hydrometeor., 1, 311-329. 
Lanicci, J. M., T. N. Carlson, and T. T. Warner, 1987: Sensitivity of the Great Plains severestorm environment to soil-moisture distribution. Mon. Wea. Rev., 115, 2660-2673.

Leung, L. R., and S. J. Ghan, 1999: Pacific Northwest climate sensitivity simulated by a regional climate model driven by a GCM. Part 1: Control simulations. J. Climate, 12, 2010-2030.

Leung, L. R., L. O. Mearns, F. Giorgi, and R. L. Wilby, 2003: Regional climate research: Needs and opportunities. Bull. Am. Meteor. Soc., 84, 89-95.

McCumber, M. C., and R. A. Pielke, 1981: Simulation of the effects of surface fluxes of heat and moisture in a mesoscale numerical model - Part 1: Soil layer.J. Geophys. Res., 86, 9929-9938.

Mesinger, F., and T. L. Black, 1992: On the impact of forecast accuracy of the step-mountain (eta) vs. sigma coordinate. Meteor. Atmos. Phys., 50, 47-60.

Misra, V., P. A. Dimeyer, and B. P. Kirtman, 2001: The Implementation of Simplified Simple Biosphere (SSiB) Scheme in the Regional Spectral Model (RSM), Technical Report, Center of Land-Atmosphere, April 2001, 31 pp.

Mo, K. C., and H. M. H. Juang, 2003: Relationships between soil moisture and summer precipitation over the Great Plains and the Southwest.J. Geophys. Res. Atmos., 108, 5.1-5. 17, doi:10.1029/2002JD002952.

Nobre, P., A. D. Moura, and L. Sun, 2001: Dynamical downscaling of seasonal climate prediction over Nordeste Brazil with ECHAM3 and NCEP's regional spectral models at IRI. Bull. Am. Meteor. Soc., 82, 2787-2796.

Pan, H. L., and L. Mahrt, 1987: Interaction between soil hydrology and boundary layer development. Bourd. Layer Meteor., 38, 186-202.

Roads, J., S. C. Chen, M. Kanamitsu, and H. Juang, 1999: Surface water characteristics in NCEP global spectral model reanalysis. J. Geophys. Res., 104, 19307-19327.

Roads, J. O., and S. C. Chen, 2000: Surface water and energy budgets in the NCEP Regional Spectral model. J. Geophys. Res. Atmos., 105, 29539-29549.

Roads, J., S. C. Chen, and M. Kanamitsu, 2003: US Regional Climate Simulations and Seasonal Forecasts. J. Geophys. Res. Atmos., 108, 8606, doi:10.1029/2002JD002232.

Roads, J., S. Chen, S. Cocke, L. Druyan, M. Fulakeza, T. LaRow, P. Lonergan, J. Qian, and S. Zebiak, 2003: The IRI/ARCs Regional Model Intercomparison over Brazil. J. Geophys. Res., 108, 9.1-9.12, doi:10.1029/2002JD003201.

Takle, E., W. J. Gutowski, R. W. Arritt, Z. Pan, C. J. Anderson, R. R. da Silva, D. Cayan, S. C. Chen, F. Giorgi, J. H. Christensen, S. Y. Hong, H. M. Juang, J. Katzfey, W. M. Lapenta, R. Laprise, G. E. Liston, P. Lopez, J. McGregor, R. A. Pielke Sr., and J. O. Roads, 1999: Project to intercompare regional climate simulations (PIRCS): Description and initial results. J. Geophys. Res., 104, 19443-19461.

Xie, P., and P. A. Arkin, 1997: Global Precipitation: A 17_year Monthly Analysis Based on Gauge Observations, Satellite Estimates, and Numerical Model Outputs. Bull. Am. Meteor. Soc., 78, 2539-2558. 